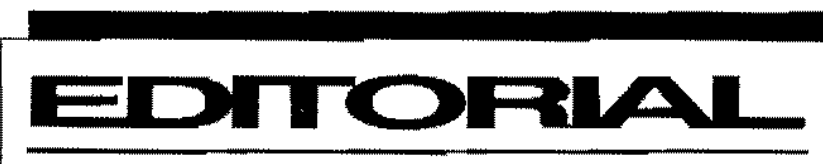

O BALANÇO DESTE PRIMEIRO ANO

A RAE, expressão da interpretação eaespiana sobre o mundo dos negócios, iniciou o ano de 1996 com desafios de grande fôlego: equilibrio financeiro, recuperaçâo da regularidade e retomada de sua identidade. As primeiras medidas foram internas e procurou-se contradizer o ditado: em casa de ferreiro o espeto é de pau. Uma reanálise de processos culminou em uma radical mudança da equipe de redação; a recuperaçăo da periodicidade regular trouxe a mudança da bimestralidade para a trimestralidade; a retomada da identidade ocasionou uma divisão da revista em seçōes que esta. belecem a tangência entre o mundo empresarial $\mathrm{e}$ a EAESP. Há muito ainda para ser feito se o objetivo for tornar a $R A E$ uma publicaçăo digna de freqüentar um número ainda maior de bibliotecas de gestäo de empresas e, mais ainda, ser a leitura imprescindivel para um número ainda maior de assinantes. Benchmarkeamos algumas revistas estrangeiras $\mathrm{e}_{4}$ ao que tudo indica, fomos copiados por outras publicacôes do ramo. Estaremos olhando com a maior atenção, em 1997, para as recomendaçőes de nosso conselho editorial. Não deveremos abandonar a divisâo em seçōes adotada em 1996, porém a linha editarial será nosso foco prioritário. No último número deste ano, estamos contemplando artigos em cinco seçőes. Organizaçăo, Recursos Humanos e Planejamento abre a revista com um artigo de Livia Barbosa sobre Cultura Organizacional. Julgamos que a importância deste artigo reside nos esforços voltados para a construção de pontes entre áreas anteriormente tratadas como estanques, como fol 0 caso da Antropologia e da Administraçăo. Administraçắo Mercadológica, um dominio em constante transformaçăa, examina as relaçöes entre suprimento global, novas tecnologias e desempenho mercadológico; Mike Kotabe, um dos autores, e professor-visitante de AustinTexas na EAESP/ FGV. Ainda em Marketing, porêm com foco em gerenciamento de banco de dados, Francisco Arantha abre um novo cenário para o tratamento das "identificaçôes". Na seçăo Administraçăo Pública, a inovadora abordagem da economia neoinstitucional é apresentada por Marcos Fernandes em seu artigo sobre politicas públicas/decisōes/estrutura organizacional/maximizaçấo de resultados. Por fim, em Administração da Produçăo e Sistemas de informaçăo, os autores Marcelo Caldeira e Henrique Luiz Corrêa analisam o uso de sistemas de programação com capacidade finita $\mathbf{e}$ estabelecem critérios para escolha dos sistemas disponiveis no Brasil. A área de finanças náo poderia estar ausente e William Eid nos apresenta resultados de sua investigação sobre o comportamento das empresas brasileiras no que tange a relação entre custos e estrutura de capital. Este número se encerra com duas resenhas de livros que, pela atualidade e relevância, deveriam ser prioridades de leitura.

0 próximo ano de 1997 se anuncia como sério e como tal será tratado. Mais mudanças, portanto, deverão ocorrer.

Prof. Roberto Venosa Diretor e Editor

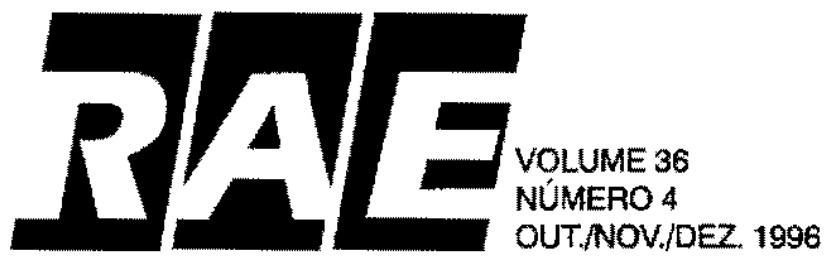

Organização, Recursos Humanos

e Planejamento

\section{Cultura administrativa: uma nova perspectiva das relaçōes entre antropologia e administração}

Livia Neves de Holanda Barbosa

O artigo explora as relaçōes entre antropologia $e$ administraçăo a partír de uma nova perspectiva. Pretende demonstrar que as possibilidades de contribuiçăo da antropologia para a administraçăo vāo além do conceito de cultura organizacional desenvolvido a partir do final da década de 1970.

The article deals with the relations between Business Administration and Anthropology in a new perspective.

It tries to demonstrate that the contribution of Antropology to Business Administration goes far beyond the idea of organizational culture, developed in the end of 1970.

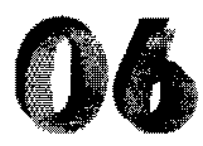

Administraçăo Mercadológica

\section{An optimal level of technology reliance on foreign partners in a global sourcing partnership: components procurement, technology management and market performance}

Masaaki Kotabe e Preet S. Aulakh

Neste artigo, os autores mostram as limitaçōes das pesquisas sobre suprimento global, examinando o impacto das atividades de inovação de processos de manufatura e suprimento de componentes no desempenho do mercado das empresas que possuem uma parceria de suprimento.

In this study, the authors address the limitations of existing global sourcing research by examining the impact of product and process innovative activities and components procurement on the market performance of firms that have a sourcing partnership arrangements.

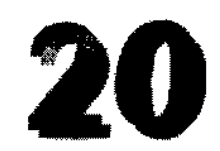

